\title{
The temporal sequence of aura-sensations in patients with complex focal seizures with particular attention to ictal aphasia
}

\author{
K KANEMOTO, D JANZ \\ From The Department of Neurology, University Hospital Rudolf-Virchow, Free University of Berlin, Berlin, \\ Federal Republic of Germany
}

SUMMARY The sequences of aura sensations in 143 patients with complex partial seizures, were analysed with special emphasis on aphasic symptoms. Anxiety, epigastric sensation and visual hallucination were experienced early in the course of the aura, while illusion of familiarity and aphasia occurred late in the course of the aura. Three groups of interconnections of aura sensations were found which corresponded possibly to the types of seizure constellations proposed by Wieser. Close interconnections between impairment of verbal comprehension during seizures and paroxysmal thought disorder, as well as between paroxysmal paraphasia and illusion of familiarity were noted. Paroxysmal aphasia in patients with complex partial seizures was characterised as a positive symptom in contrast to stable aphasia.

The phenomenology of epileptic aphasia has been intensively studied by earlier authors. ${ }^{1-13}$ Nevertheless, except for McKeaver et al ${ }^{14}$ and some sporadic case reports, ${ }^{15-22}$ aphasic phenomena during seizures have not attracted much attention recently. The statement of Critchley that epileptic aphasia is dispensable as a source of information to elucidate the structure of language disorder has not yet lost its influence. ${ }^{23}$

We believe, however, that the temporal sequence of aura sensations within the aura could reveal dynamic linkage between various brain functions. This follows the principle pioneered by $\mathrm{Janz}^{24}$ that this sequence follows definite patterns. As Castell has already pointed out, ${ }^{5}$ the study of ictal aphasia and aura sequences could shed a new light on interconnections between the language system and other brain functions by supplementing the deficiencies of "static" neuropsychology.

Because few authors have paid attention to the chronological sequences of aura sensations within the aura, ${ }^{24-27}$ we have tried to obtain a comprehensive survey of interrelations between aura sensations. We have also studied the specific position of epileptic aphasia from the viewpoint of aura sequences.

Address for reprint requests: Dr Kousuke Kanemoto, Utano National Hospital, Ukyo-ku, Narutaki, Ontoyama-cho 8, Kyoto-fu, Kyotoshi, Japan

Received 10 May 1987 and in revised form 4 August 1988. Accepted 8 August 1988

\section{Materials and methods}

We analysed auras of 143 patients with complex foca seizures retrospectively from the case notes in our clinic between 1973 and 1987. Patients directly treated by one of the authors (D.J.) were selected for our study because adequate and homogeneous documentation of auras were indispens able. Among these, 24 patients complained of aphasic: symptoms during the aura (table 1).

Aphasia is defined in our study as follows: Impairment of comprehension, paraphasia, or word finding difficulty. Speech arrest and vocalisation without other signs of speech

Table 1 Frequency of different aura-sensations in our patients

\begin{tabular}{lcc}
\hline & $N$ & $\%$ \\
\hline Epigastric & 50 & 35 \\
Familiarity & 45 & 31 \\
(Déjà vu) & 28 & 19 \\
Aphasia & 24 & 17 \\
Anxiety & 23 & 16 \\
Thought-disorder & 19 & 13 \\
"Es" & 16 & 10 \\
Visual & 12 & 8 \\
Somatosensory & 12 & 8 \\
Gustatory & 12 & 8 \\
Porropia-Porracousia & 8 & 6 \\
Olfactory & 7 & 5 \\
Auditory & 7 & 5 \\
Dysarthria & 4 & 3 \\
Others & 5 & 4 \\
No aura & 31 & 22 \\
Total N & 143 & \\
\hline
\end{tabular}


disturbance are not counted as ictal aphasia, in accordance with earlier studies suggesting their topographical and clinical independence from aphasic symptoms. ${ }^{82829}$ Besides ictal aphasia, some other aura sensations should also be explained. "Es" ${ }^{24}$ is non-specific warning difficult to express otherwise. "Es" in German corresponds approximately to "it" in English. We call the aura sensation "Es", if the experience can not be put into more precise terms. Patients can only say "It is a strange, indescribable feeling." Epigastric sensation refers to sensations rising from epigastric area. With Porropsia and Porrakousia the objects seem to move away from the patient or sounds seem to come from a distant place. In thought disorder there is crowding of thought, forced-thinking ${ }^{2}$ and other changes in the quality of thoughtprocess (for example, acceleration of thought). Illusion of familiarity: Besides déjà vu and jamais vu, this includes all the experiences of altered familiarity to the environment. Because déjà vu or jamais vu indicates visual familiarity literally, we adopt illusion of familiarity as a wider concept applicable to other modalities of sensations as well as visual.

Aura sequences were reconstructed on the basis of the patient's own report supplemented by the statements of witnesses. The same type of aura sequence in a patient was regarded as a unit. Eighty-one patients had only one type of aura sequence. Twenty-six patients had two types of aura sequences and five had more than two types. Thirty-one patients were recorded altogether $(31 \times 0+81 \times 1+26 \times$ $2+2 \times 3+2 \times 4+1 \times 5)$.

EEG foci were determined interictally through multiple surface recordings.

\section{Results}

\section{(A) Content and frequency of aura sensations}

Frequencies of different aura sensations in our study are summarised in table 1. Epigastric aura and illusion of familarity were the most frequent. Ictal aphasia, anxiety and thought-disorder followed them by a wide margin.

Among auditory hallucinations, we recorded six cases of elementary (machine sounds etc.) and one case of complex type (voice). Half of the visual hallucinations were elementary (coloured spot etc.) and half were complex (scene or picture). With regards to the ictal thought-disorder, five patients reported acceleration of thought ("The thought accelerates itself more and more rapidly, as if it began to gallop"). It was similar to crowding of thought, but the accelerated thought here lacked the strangeness characteristic of crowding of thought. Another six patients complained of a kind of forced thinking ("Thoughts push their way in my head and I cannot get rid of them"). This forced thinking was often reported to have an iterative nature ("It is always the same idea that comes and goes in my head"), but ordinarily they could not formulate what it was. Furthermore, a variety of altered thoughtprocesses was experienced ("Thoughts blended into one another," "I could think only slowly and all ideas went out of me," "The thought was hardened as if it
Table 2 Distribution of laterality of EEG focus and type of aura sensation

\begin{tabular}{lrcccc}
\hline & Left & Right & Both & No & Total \\
\hline Epigastric & 22 & 13 & 5 & 10 & 50 \\
Familiarity & 16 & 12 & 6 & 11 & 45 \\
$\quad$ (déjà vu) & 8 & 8 & 3 & 9 & 28 \\
Aphasia & 16 & 1 & 2 & 5 & 24 \\
Anxiety & 9 & 5 & 3 & 6 & 23 \\
Thought-disorder & 14 & 0 & 2 & 3 & 19 \\
"Es" & 5 & 7 & 1 & 3 & 16 \\
Total & 49 & 34 & 11 & 49 & 143 \\
\hline
\end{tabular}

Only aura sensations occurring in more than $10 \%$ of patients are listed.

were a material"). Ictal aphasia consisted of eight cases with impairment of comprehension without paraphasia, five cases of paraphasia with simultaneous impairment of comprehension, nine cases of paraphasia with intact comprehension and two cases with difficulty in finding words. It should be noted also that the paraphasias reported or witnessed in our study contained neologisms in most cases.

(B) Correlation between laterality of EEG foci and type of aura (table 2)

Among our 143 patients, $34 \%$ had only left foci; $24 \%$, only right foci. In comparison, left foci predominated in patients with ictal aphasia (67\%) and ictal thought disorder $(73 \%)$. Application of the $\chi^{2}$ test indicated a significant association between these two aura sensations and a focus in the left cerebral hemisphere $\left(\chi^{2}=\right.$ $11 \cdot 5,15 \cdot 43$ respectively, $p=0.05)$. In the patients with thought disorder, 14 had temporal EEG foci and two had extratemporal foci. We did not find a predominance of right foci among patients suffering from illusion of familiarity. Application of the $\chi^{2}$ test fails to suggest any significant associations between aura sensations listed in table 2 and a focus in the right hemisphere.

\section{(C) The sequence of aura sensations}

We examined the distribution of auras with only one and more than one aura sensation. Especially "Es"aura $(69 \%)$ but also epigastric sensations (55\%), olfactory sensations $(57 \%)$ and somatosensory sensations $(58 \%)$ tended not to be combined with other aura sensations. On the contrary, anxiety, gustatory sensations, thought disorder, ictal aphasia, dysarthria and visual hallucinations manifested themselves mostly in combination with other aura sensations (more than $80 \%$ ).

Table 3 shows the time sequence of aura sensations within auras with more than one aura sensation. More than $70 \%$ of illusion of familiarity, ictal aphasia, dysarthria and porropsia-porracousia occurred at the end of the aura sequence. "Es"-aura, anxiety and epigastric sensation were almost exclusively found at 
Table 3 Temporal sequences of aura sensations within auras

\begin{tabular}{|c|c|c|c|c|c|}
\hline \multirow[b]{2}{*}{ Aura type } & \multicolumn{3}{|c|}{$\begin{array}{l}\text { (A) auras consisting of } \\
\text { more than one aura } \\
\text { sensation }\end{array}$} & $\begin{array}{l}\text { (B) auras } \\
\text { consisting of only } \\
\text { one aura sensation }\end{array}$ & \multirow[b]{2}{*}{ Total } \\
\hline & \multicolumn{3}{|c|}{ Beginning Middle End } & & \\
\hline Epigastric & 19 & 2 & 2 & 27 & 50 \\
\hline Familiarity & 3 & 5 & 22 & 15 & 45 \\
\hline Aphasia & - & 1 & 21 & 2 & 24 \\
\hline Anxiety & 20 & - & - & 3 & 23 \\
\hline Thought-disorder & 4 & 9 & 5 & 1 & 19 \\
\hline "Es" & 5 & - & - & 11 & 16 \\
\hline Visual & 6 & 3 & 2 & 1 & 12 \\
\hline Somatosensory & 2 & 0 & 3 & 7 & 12 \\
\hline Gustatory & 2 & 7 & 1 & 2 & 12 \\
\hline Porropsia- & & & & & \\
\hline Porracousia & - & 1 & 4 & 3 & 8 \\
\hline Olfactory & 1 & 1 & 1 & 4 & 7 \\
\hline Auditory & 2 & 1 & 1 & 3 & 7 \\
\hline Dysarthria & - & 1 & 3 & - & 4 \\
\hline
\end{tabular}

the start-position of an aura sequence. The startposition was also favoured by visual hallucination, auditory hallucination and somatosensory sensation. Gustatory sensation and thought disorder were found most frequently in the transitional position within a given aura.

Certain patterns of how aura sensations preceded or followed each other tended to occur more often than other patterns. The main routes of aura sequence are demonstrated in fig 1 . (Only the combinations recorded more than twice are depicted). Epigastric sensation was followed mainly by either gustatory sensation, illusion of familiarity, or thought disorder. Thought disorder was in turn followed by either illusion of familiarity, ictal aphasia, or dysarthria and was preceded by either epigastric sensation or anxiety. Gustatory sensation developed mainly from epigastric aura and progressed into illusion of familiarity. Visual hallucination was chiefly combined with illusion of familiarity and anxiety. While illusion of familiarity always succeeded visual hallucination, if they were combined within a given aura, visual hallucination and anxiety were experienced simultaneously in most cases and it was difficult to decide which preceded the other. Illusion of familiarity was followed only by ictal aphasia, although it was preceded by most of the other aura sensations. Ictal aphasia was experienced almost always at the end-position within a given aura sequence.

The two main precursors of ictal aphasia, namely thought disorder and illusion of familiarity, tended to develop into different types of ictal aphasia (table 4). In patients with ictal aphasia following thought disorder, paraphasia without impairment of verbal comprehension was reported more frequently than impairment of verbal comprehension without paraphasia. The tendency was reversed in patients with ictal aphasia following thought disorder. In addition, in

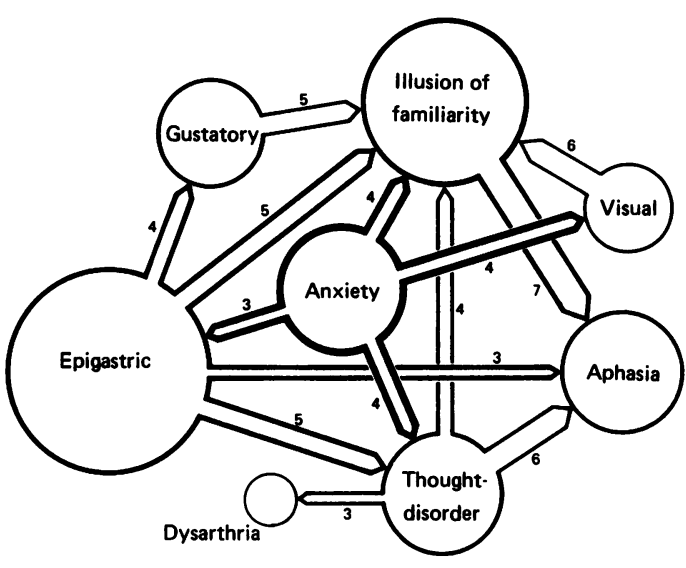

Fig 1 The size of each circle corresponds to the number of patients experiencing the respective aura-sensation. The thickness of arrows corresponds to the number of combinations between the respective aura-sensations. The numbers accompanying each arrow are the numbers of corresponding combinations. Only combinations recorded more than twice are depicted.

five out of seven cases with illusion of familiarity preceding ictal aphasia, familiarity was altered only to verbal stimuli.

\section{Discussion}

Except for thought disorders, frequencies of aura sensations in our study correspond fairly well with those of previous reports. ${ }^{30-32}$ The results which our study and previous studies have in common are as follows: (1) The high frequency of epigastric sensation among aura sensations, (2) the frequency of anxiety $(14-19 \%),(3)$ the frequency of ictal aphasia $(16-17 \%)$, (4) the frequency of gustatory-olfactory sensation (13$15 \%),(5)$ the ratio of elementary to complex auditory hallucination $(5: 1-6: 1)$, (6) the ratio of elementary to complex visual hallucinations $(1: 1)$. Additionally, the ratio of the left, bilateral and right foci in our 143 patients (52:12:36) agreex well with that of Currie $e t$ al's study $(52: 19: 29) .{ }^{30}$ Thus, our group of patients apears to be representative of patients with complex focal seizures, with regard to their aura experiences.

Our study leads us to several conclusions, which

Table 4 Correlation between types of ictal aphasia and two types of aura-sensation-sequence

Only paraphasia Only comprehension-impairment

FAM $\rightarrow \mathrm{APH}^{*}(\mathbf{N})$ THO $\rightarrow$ APH $+(N)$

1
6

*: Ictal aphasia preceded by illusion of familiarity $t:$ Ictal aphasia preceded by ictal thought-disorder 
have not been pointed out previously. First, the frequency of thought disorder is strikingly high in our study $(13 \%)$, especially considering that previous authors ${ }^{30-32}$ did not adopt it as an independent item. Weber $e t$ al,$^{26}$ who studied aura psychopathologically, did pay attention to thought disorder, but did not note the predominance of left foci in thought disorder. Unlike previous authors, we included patients with extratemporal foci as well as those with temporal foci in our study. This alone, however, can not explain the discrepancy between our study and the previous studies, because the current series contained only a limited number of patients with extratemporal EEG foci in patients with thought disorder.

The predominant side of EEG foci in patients with déjà vu has been long disputed. In contrast to Mullan et $a \ell^{33}$ and Gupta $e t a l,{ }^{34}$ we as well as Cole et $a \beta^{35}$ did not find a predominance of right EEG foci among patients suffering from déjà vu.

Some of the rules about the sequences of aura sensations have been already reported in previous studies. ${ }^{24}{ }^{25} \mathrm{Janz}^{24}$ and Paillas $e t$ al $l^{5}$ pointed out that visual hallucination is experienced early in the course of aura sequences. Janz ${ }^{24}$ and Hallen ${ }^{27}$ mentioned the precedence of anxiety and epigastric sensations to the gustatory and olfactory sensations. The finding that illusion of familiarity occupies the endposition of an aura sequence was described by Janz. ${ }^{24}$ However, previous studies have not examined the positions occupied by aphasia and thought disorder within aura sequences. Nor have they performed a comprehensive survey of aura sequences in patients with complex focal seizure. To offer such a survey, interrelations between main aura sensations including thought disorder and aphasia are schematically redrawn in fig 2 . Three separate flows of aura sequences can be seen in the figure. After starting from anxiety, the flow going through visual hallucination does not join other aura sensations before reaching illusion of familiarity. Within the group of aura sensations starting from epigastric aura, the same is true for the flow going through gustatory sensation. The flow going through thought disorder has also an independent course from the other aura sequences on the way from epigastric sensation to aphasia. In view of this flow of aura sequences, three different functional circuits within the limbic system can be suggested: (1) Visual function $\rightarrow$ memory function, (2) autonomic function $\rightarrow$ alimentary function $\rightarrow$ memory function $\rightarrow$ language function and (3) autonomic function $\rightarrow$ thought function $\rightarrow$ memory function $\rightarrow$ language function. This grouping of aura sensations corresponds, at least to some extent, to the types of seizure constellation proposed by Wieser: ${ }^{36}$ The first ring to Wieser's type $\mathrm{V}$ (posterior neocortical type), the second ring to Wieser's type I and type II (temporobasal type and

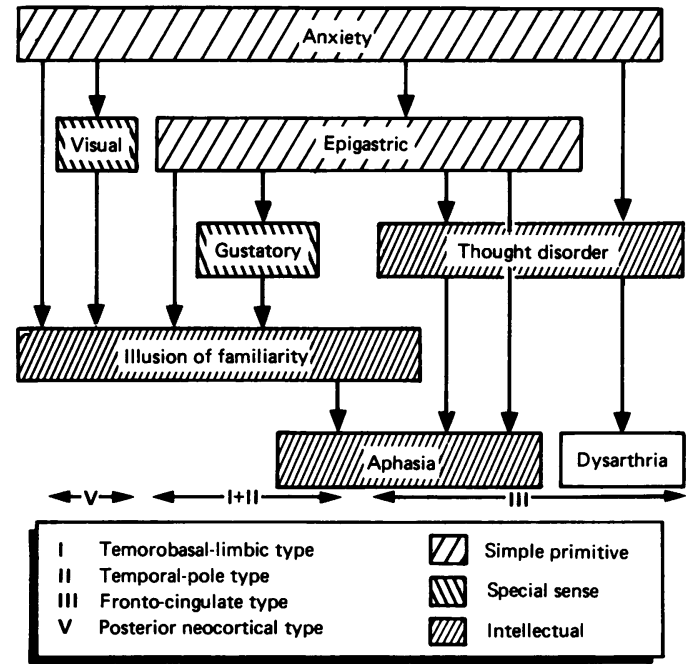

Fig 2 Schematic representation of fig 1 .

temporal-pole type) and the third ring to Wieser's type III (fronto-cingulate type).

Taylor $e t a \boldsymbol{\beta}^{\beta}$ classified aura sensations tentatively into three groups, namely "simple primitive", "special senses" and "intellectual". The first group of aura sensations corresponds to anxiety, epigastric sensation and "Es" in our study. Auditory hallucination, visual hallucination and gustatory sensation belong to their "special senses". Thought-disorder, illusion of familiarity and possibly aphasia correspond to "intellectual auras". According to our study, aurasequences always develop unidirectionally from "simple primitive" to "special senses" and from "special senses" to "intellectual" (fig 2). Taylor speculated that most patients with temporal lobe epilepsy with early onset experienced simple primitive aura and that this could reflect a change in temporal lobe function between childhood and adult life. If that is the case, the aura sequence is supposed to mimic ontogenetical development in view of the rule sumarised by us.

In view of the close interrelations between paraphasia and illusion of familiarity and between thought disorder and impairment of verbal comprehension, it could be supposed that at least some parts of ictal paraphasia and ictal impairment of comprehension stem from a disinhibition of memory- and thoughtprocess respectively. This hypothesis is supported also by the fact that some cases with paraphasia, as in the cases of $\mathrm{Kisker}^{6}$ and Wilson et al, ${ }^{21}$ characteristically developed from a preceding state of readiness, which should be regarded as some kind of illusion of familiarity limited to words. In such cases, the paraphasia and illusion of familiarity interacted with each 
other so closely that the manifestation of speech symptoms could be interpreted as an expression of illusion of familiarity. To some extent, this was also true of the interrelation between paroxysmal thought disorder and impairment of verbal comprehension. This is to say, most of our patients not only lost some parts of their ability but also experienced something extra during the ictal aphasia. Therefore, if we call what is lost through illness negative symptoms and what appears extra positive symptoms, ictal aphasia in our patients could be described as a positive symptom.

Contrary to Critchley's opinion, ictal aphasia relating to limbic seizures contrasted well with defect asphasia caused by cerebral infarction and provided information that could not be obtained through studies of stable aphasia.

The first author wishes to thank his deceased wife, Yoshiko, for her help in transcribing raw materials into a definite format and Mrs. Susan Hodge in correcting the English manuscript.

\section{References}

1 Jackson JH. On slight and severe cerebral paroxysms (epileptic attacks) with auditory warning. Lancet 1894;ii:182.

2 Penfield W, Jasper H. Epilepsy and Functional Anatomy of the Human Brain. Boston: Little, Brown, 1954:366-7.

3 Chavany, JA, Lobel G, Hagenmuller D. Etude clinique des troubles du langage d'essence épileptique. Presse Méd 1956; 64:1449-51.

4 Hécaen H, Piercy M. Paroxysmal dysphasia and the problem of cerebral dominance. J Neurol Neurosurg Psychiatry 1956; 19:194-201.

5 Castells C, Fuster B, Maslenikow V. Crisis disfasicas de origen temporal. Acta Neurol Latinoam 1957;3:172-89.

6 Kisker KP. Sprachliche Stereotypien bei TemporallappenEpilepsie (Ein Beitrag zur Konstitution verbaler Sprachteile). Nervenarzt 1957;28:366.

7 Bingley T. Mental symptoms in temporal lobe epilepsy and temporal lobe gliomas. Acta Psychiatr Neurol Scand Suppl 1958;120:96-101.

8 Penfield WG, Roberts L. Speech and Brain Mechanisms. Prinston, NJ: Prinston University Press, 1959:88-9.

9 Hécaen $H$ Angelergues. Epilepsie et troubles du langage. Encéphale 1960;49:138-69.

10 Alajouanine T, Sabouraud A. Les pertubations paroxystiques de langage dans l'épilepsie. Encéphale 1960;49:95-133.

11 Boudouresques J, Roger J, Gastaut H. Crises aphasiques subintrantes chez un épileptique temporal. Rev Neurol (Paris) 1962;106:381-93.

12 Serafetidines EF, Falconer MA. Speech disturbances in temporal lobe seizures: a study in 100 epileptic patients submitted to anterior temporal lobectomy. Brain 1963;86:333-46.
13 Acevedo de Mendilaharsu S, Bogacz J, Mendilaharsu C. Etude électroclinique ictale des crises dysphasiques provoquées par activation cardiazolique. Neuropsychologia 1964;1:299-312.

14 McKeever M, Holmes GL, Russmann BS. Speech abnormalities in seizures: a comparison of absence and partial complex seizures. Brain Lang 1983;19:25-32.

15 De Pasquet EG, Gaudin ES, Bianchi A. Prolonged and monosymptomatic dysphasic status epilepticus. Neurology 1976;26: 244-7.

16 Hamilton NG, Matthews T. Aphasia: The sole manifestation of focal status epilepticus. Neurology 1979;29:745-8.

17 Racy A, Osborn MA, Vern BA, Molinari GF. Epileptic asphasia: first onset of prolonged monosymptomatic status epilepticus in adults. Arch Neurol 1980;37:419-22.

18 Dinner DS, Lueders H, Ledermann R, Gretter TE. Aphasic status epilepticus: A case report. Neurology 1981;31:888-90.

19 Gilmore RL, Heilman KM. Speech arrest in partial seizures: Evidence of an associated language disorder. Neurology 1981; 31:1016-9.

20 Marrosu F, Brundu A, Rachele MG, Marrosu G. Epileptic aphasia as dynamic disturbance: a case report. Acta Neurol 1983;5:43-6.

21 Wilson A, Petty R, Perry A, Clifford Rose F. Paroxysmal language disturbance in an epileptic treated with clobasam. Neurology 1983;33:652-4.

22 Rosenbaum DH, Siegel M, Barr WB, Rowan AJ. Epileptic aphasia. Neurology 1986;36:822-5.

23 Critchley M. Troubles de la parole dans les cas d'épilepsie. Encéphale 1960;49:134-7.

24 Janz D. Die Epilepsien. Thieme, Stuttgart 1969.

25 Paillas JE, Vigouroux R, Darcourt G, Naquet R. Considerations sur l'epilépsie occipitale. Neurochirurgie 1959;5:3-15.

26 Webber WC, Jung CR. Uber die epileptische Aura. Z Gesamte Neurol Psychiatr 1940;170:211-65.

27 Hallen O. Zur Differenzierung der psychomotorischen Anfälle in klinische Formen Dtsch Z Nervenheilkd 1962;183:199-217.

28 Kawai I, Ohashi $H$. Ictal speech disturbance and cerebral dominance. Stud Phonol 1975;9:40-4.

29 Penfield W, Rasmussen T. Vocalisation and arrest of speech. Arch Neurol Psychiatry 1949;61:21-7.

30 Currie SH, Heathfield KWG, Henson RA, Scott DF. Clinical course and prognosis of temporal lobe epilepsy-survey of 666 patients. Brain 1971;94:173-90.

31 King DW, Ajmonemarsan CA. Clinical features and ictal patterns in epileptic patients with EEG temporal lobe foci. Ann Neurol 1977;2:138-47.

32 Meyer-Mickeleit RW. Die Dämmeratacken als charakteristischer Anfallstyp der temporal Epilepsie (psychomotorische Anfälle, Äquivalente, Automatismen). Nervenarzt 1953;24:331-46.

33 Mullan S, Penfield W. Illusion of comparative interpretation and emotion. Arch Neurol 1959;81:269-84.

34 Gupta AK, Jeavons PM, Hughes RC, Covanis A. Aura in temporal lobe epilepsy: clinical and electroencephalographic correlation. J Neurol Neurosurg Psychiatry 1983;46:1079-83.

35 Cole M, Zangwill OL. Déjà vu in temporal lobe epilepsy. J Neurol Neurosurg Psychiatry 1963;26:37-8.

36 Wieser HG. Electroclinical features of the psychomotor siezure. Stuttgart, Fischer, 1983:193-206.

37 Taylor D. Lochery M. Temporal lobe epilepsy: origin and significance of simple and complex auras. $J$ Neurol Neurosurg Psychiatry 1987;50:673-81. 